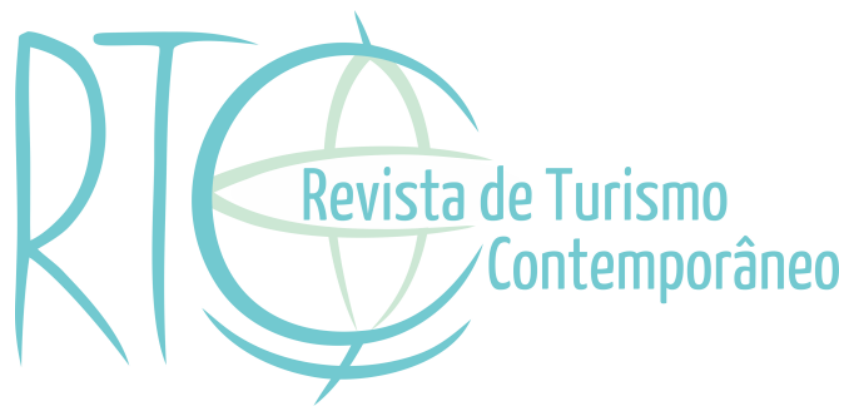

\title{
Interface entre municípios, Turismo e eventos: Um olhar para a microrregião do Litoral Sul Potiguar e impactos possíveis
}

\section{Interface between municipalities, Tourism and events: $A$ view at the Potiguar South Coast Microregion and possible impacts}

Darlyne Fontes Virginio

Professora de Turismo e Eventos do Instituto Federal de Educação, Ciência e Tecnologia do Rio Grande do Norte - IFRN, Natal/RN, Brasil

E-mail: darlynefontes@yahoo.com.br

Yohana Silva Moreira

Estudante com ênfase em Turismo e Eventos do Instituto Federal de Educação, Ciência e Tecnologia do Rio Grande do Norte - IFRN, Natal/RN, Brasil

E-mail: yohanamoreira13@gmail.com

Paulo Messias da Paz de Lima

Estudante do Instituto Federal de Educação, Ciência e Tecnologia do Rio Grande do Norte IFRN, Natal/RN, Brasil

E-mail: paulomessias.paz@gmail.com

\section{Laynara Silva Chacon}

Estudante do curso técnico integrado em Eventos no Instituto Federal de Educação, Ciência e Tecnologia do Rio Grande do Norte - IFRN, Natal/RN, Brasil

E-mail: laynarachacon02@gmail.com 


\section{RESUMO}

O turismo de eventos pode ser considerado uma das grandes molas propulsoras do turismo, especialmente, em períodos de baixa estação, uma vez que ele é o segundo segmento que mais gera fluxo de movimentação turística (Ministério do Turismo [MTur], 2013). Assim, abarcar os impactos dessa atividade no contexto da Microrregião do Litoral Sul Potiguar - MRLS torna-se inerente a este estudo, principalmente, por ser pioneiro na região que carece de pesquisas mais aprofundadas sobre turismo, eventos e impactos. Dessa forma, seu objetivo foi compreender qual a interface dos municípios da Microrregião do Litoral Sul Potiguar com o turismo, os eventos e os impactos possíveis que podem ser gerados em seus principais destinos. Outrossim, o presente estudo se caracteriza como descritivo e de caráter exploratório tendo como base pesquisas em fontes bibliográficas, artigos científicos, entre outros documentos emitidos por entidades do setor. O recorte espacial é composto por 3 (três) municípios turísticos do litoral sul do Rio Grande do Norte, são eles: Baía Formosa, Canguaretama e Tibau do Sul, já que concentram os principais eventos que fomentam a vinda de turistas para a Microrregião. Assim, foi possível identificar a interface dos municípios da MRLS com o turismo, quais são os principais eventos realizados e que impactos possíveis eles podem gerar, sendo o turismo de eventos um dos segmentos que mais recebem atenção nos períodos de baixa temporada, visando o incremento no fluxo turístico local.

Palavras-chave: Eventos. Turismo. Impactos. MRLS.

\section{ABSTRACT}

Event tourism can be considered one of the main propulsive springs of tourism, especially in low season periods, since it is the second segment that generates the most flow of tourist movement (Ministério do Turismo [MTur], 2013). Thus, to cover the impacts of this activity in the context of the Potiguar South Coast Microregion - MRLS is inherent to this study, mainly because it is a pioneer in the region that needs more deepen research on tourism, events and impacts. In this way, the objective was to understand the interface of the municipalities of the Potiguar South Coast Microregion with tourism, the events and possible impacts that can be generated in their main destinations, also, the present study is characterized as descriptive and exploratory based on research in bibliographic sources, scientific articles, among other documents issued by entities of the sector. The spatial clipping is composed of 3 (three) tourist municipalities on the southern coast of Rio Grande do Norte, which are: Baía Formosa, Canguaretama and Tibau do Sul, since they concentrate the main events that encourage the arrival of tourists to the Microregion. Thus, it was possible to identify the interface of MRLS municipalities with tourism, what are the main events and what possible impacts they can generate, with event tourism being one of the segments that receive the most attention during low season periods, aiming to increase in the local tourist flow.

Keywords: Events. Tourism. Impacts. MRLS. 


\section{INTRODUÇÃO}

Evento se define por um conjunto de atividades que envolvem o planejamento de diversos segmentos, e que procuram atingir um determinado público-alvo com medidas concretas, objetivando resultados pré-projetados (Britto \& Fontes, 2006).

Considerando que os eventos têm apresentado um crescimento bastante significativo no Brasil nos últimos doze anos, especificamente $14 \%$ ao ano, conforme os dados apresentados no II Dimensionamento Econômico da Indústria de Eventos no Brasil (Associação Brasileira de Empresas de Eventos [ABEOC] \& Serviço Brasileiro de Apoio às Micro e Pequenas Empresas [SEBRAE], 2013), e que o turismo de eventos pode ser tido como um fator relevante para a sazonalidade dos destinos, pois, acredita-se que ao serem realizados no período de baixa estação, os eventos podem elevar o fluxo de turistas, é que denotasse a perpetuação de um movimento das atividades relacionadas ao setor do comércio e de serviços local naqueles meses em que o turismo de lazer é mais fraco, alavancando a economia e propiciando mais oportunidades de ocupação.

Com isso, entende-se o turismo de eventos como a parte do turismo que leva em consideração o critério relacionado ao objetivo da atividade turística. É aquele praticado com interesse profissional e cultural por meio de congressos, convenções, simpósio, feiras, encontros culturais, reuniões internacionais, entre outros, e é uma das atividades econômicas que mais crescem no mundo (Hoeller, 2001).

Além de ser considerado um dos segmentos do turismo que mais contribuem para geração de emprego, renda e impostos no Brasil, trata-se de uma das ramificações do turismo que cuida dos diversos eventos que acontecem nas mais distintas áreas. Por isso, acredita-se que o turismo de eventos pode contribuir para uma possível regularidade no mercado turístico, já que os eventos tendem a ser realizados nas baixas temporadas. Ademais, esse setor apresenta perspectivas de crise reduzidas, visto que, normalmente, em épocas de crise acontece o maior número de eventos, diante da necessidade de realizar reuniões para solucionar os problemas (Andrade, 2013).

Destarte, observa-se que o turismo de eventos conquistou um importante papel na economia da região Nordeste e, contribui de modo significativo para o Rio Grande do Norte $(\mathrm{RN})$, especialmente, na cidade do Natal, que vem mostrando significativamente sua participação no setor de eventos. Corroborando com o estudo realizado pela ABEOC e SEBRAE (2013), a Federação do Comércio de Bens Serviços e Turismo do Rio Grande do Norte [FECOMÉRCIO/RN] cita como exemplo o período do Carnatal na cidade do Natal- 
$\mathrm{RN}$, no ano de 2015, em que foram gerados cerca de 54,8 milhões de reais. Pouco mais de $40 \%$ dos participantes deste evento eram turistas e contribuíram com aproximadamente 43 milhões de reais, enquanto os natalenses participaram com 11 milhões. (FECOMÉRCIO/RN, 2015).

Tendo em vista, ainda, a relevância e, ao mesmo tempo, os impactos causados pelo turismo de eventos, se faz necessário compreender quais os eventos realizados nos municípios da Microrregião do Litoral Sul Potiguar, que é composta por 10 (dez) municípios, dentre eles 3 (três) com representativo fluxo turístico para o RN, que são: Baía Formosa, Canguaretama e Tibau do Sul. Com isso, é importante obter um olhar sobre os eventos e os impactos possíveis que podem ocorrer nesses destinos advindos do fluxo turístico. Dessa forma, o referido estudo tem como pergunta-problema: qual a interface dos municípios da microrregião do Litoral Sul Potiguar com o turismo, os eventos e os impactos possíveis que podem ser gerados em seus principais destinos?

Com o objetivo de compreender qual a interface dos municípios da microrregião do Litoral Sul Potiguar com o turismo, os eventos e os impactos possíveis que podem ser gerados em seus principais destinos, o presente estudo ancorou-se nos seguintes procedimentos metodológicos: foi realizada uma pesquisa descritiva de caráter exploratório com base em acervo bibliográfico, artigos científicos e demais estudos de entidades sobre eventos, turismo e turismo de eventos. O estudo também contou com informações complementares, a partir da aplicação e análise de questionários junto às secretarias de turismo dos municípios pesquisados.

A partir das informações coletadas, foram elaborados quadros representativos para compreender o contexto do turismo nos municípios da MRLS e dos eventos neles realizados. O estudo buscou, ainda, elencar os principais eventos que são realizados nos 10 municípios da microrregião, apontando para um panorama mais próximo de um calendário de eventos regional. Logo após, obteve-se um ranking contendo os 10 principais eventos realizados nos 03 municípios turísticos (eventos estes, capazes de incrementar o fluxo turístico local).

O estudo se justifica devido a importância que o setor de eventos representa para o país, já que é responsável pela geração de mais de $\mathrm{R} \$ 48$ bilhões em impostos, conforme aponta o estudo realizado no ano de 2013 pela ABEOC e SEBRAE. Esse impacto econômico pode acarretar benefícios e/ou malefícios para a localidade, especialmente, por saber que o turismo de eventos é tido como forma de promover a interação das pessoas, além de contribuir para geração e o fortalecimento das relações culturais, industriais, comerciais, ao mesmo tempo em que gera fluxos de deslocamento e visitação (Britto \& Fontes, 2006). Isso 
posto, é essencial entender a importância do turismo e dos eventos para o progresso de destinos, considerando uma provável influência destes no desenvolvimento social, econômico e ambiental. Com isso espera-se que esta pesquisa possa auxiliar em uma melhor compreensão a respeito do turismo e dos eventos que impactam no fluxo local, especialmente, pela carência de estudos e pesquisas voltados a MRLS, ainda que de forma inicial e conceitual.

\section{REFERENCIAL TEÓRICO}

\subsection{Eventos e Turismo: abordagens conceituais}

Evento, em seu sentido mais popular, é tido como um acontecimento, um acaso, uma eventualidade. Ao assimilar e interpretar esse conhecimento pode-se dizer que evento, no geral, é caracterizado como "qualquer acontecimento que foge à rotina, sempre programado para reunir um grupo de pessoas" (Serviço Nacional de Aprendizagem Comercial [SENAC], 2000), ou seja, tudo que acontece, e que envolve pessoas no ambiente em que essas pessoas estão inseridas é um evento. Giacaglia (2003, p. 03) afirma que,

com a finalidade de ampliar a esfera de seus relacionamentos inerentes ao convívio em família, no trabalho, na escola, ou no lazer, e de quebrar a rotina dos afazeres diuturnos, o homem cria, organiza e participa de reuniões, que são genericamente chamadas de eventos.

Em seu sentido mais amplo, a palavra evento envolve pessoas tanto na sua organização e preparação quanto na participação propriamente dita. É uma forma efetiva de integração de ideias, conceitos, conhecimentos e também de promover produtos e serviços das organizações. Assim para Canton (2009, p. 320), eventos são

\footnotetext{
um acontecimento planejado, em determinado tempo e local, envolvendo e mobilizando uma comunidade, buscando a integração, difusão e sensibilização entre quem participa e o objetivo que se pretende alcançar. O público é definido em função de características específicas, ou seja, atividade ou profissão, nível socioeconômico ou cultural, faixa etária, sexo, localização geográfica ou por alguma atração especial.
}

Outra característica dos eventos é o fator econômico envolvido, já que no caso de eventos internacionais que, em sua maioria, atraem um grande público, isso pode contribuir grandemente com a economia local (Matias, 2013). Atualmente, os eventos, em função dos objetivos fixados, do grande número de pessoas que envolvem e das diversas expectativas e necessidades que essas pessoas apresentam, tornaram-se uma importante atividade econômica e social, que deve ser tratada de forma profissional. Considerando, ainda, que um evento surge para, resolver um problema, propor uma solução, discutir algo em que não há consenso e/ou promover uma mudança. 
Percebe-se que todas essas conceituações têm semelhanças, mas é importante saber que a criação de um evento implica, principalmente, no aproveitamento das características originais da localidade com predisposição a sediá-lo, pois o objetivo de um evento não é apenas agradar seu público-alvo, mas corroborar para a circulação de divisas da localidade receptora, divulgar os atrativos turísticos locais e fomentar uma cadeia produtiva ao seu redor.

Em relação aos eventos e sua relação com o setor do turismo, o segmento de eventos torna-se relevante para ampliar, áreas de agências, hotéis, restauração e transporte na expansão do volume de negócios desenvolvidos pelo setor.

De acordo com a Lei Geral do Turismo $\mathrm{n}^{\circ} 11.771$ (2008), considera-se turismo as atividades realizadas por pessoas físicas durante viagens e estadas em lugares diferentes do seu entorno habitual, por um período inferior a 1 (um) ano, com a finalidade de lazer, negócios, entre outros.

Embora para muitos o turismo seja visto apenas como "indústria de viagens de prazer", trata-se de algo mais complexo do que um simples negócio ou comércio. Um valioso recurso para definir o termo "Turismo" é recorrer a sua etimologia. Assim, vale notar que, no momento de seu surgimento, o substantivo turismo é um neologismo que expressa a ação de um determinado verbo, To tour, que significa "dar uma volta", mas que já tinha uma conotação específica. To make a tour significava fazer percurso de ida e volta com características peculiares quanto aos locais a serem visitados, ao tempo de permanência neles e as motivações tanto para a viagem quanto para a estada (Barretto, 2012).

O turismo se modifica de forma rápida, refletindo-se sobre outros setores econômicos e ajudando a diversificar essas atividades, dessa forma, pode-se dizer que turismo é uma atividade que envolve deslocamento motivado por uma finalidade específica, seja ela, cultural, para lazer, negócios, etc. E esse deslocamento deve ter um tempo mínimo e máximo de permanência.

Ações como a melhoria da infraestrutura básica para receber turistas e investimentos em entretenimento fazem com que os visitantes passem mais tempo na localidade (Lei Geral do Turismo $\left.\mathrm{n}^{\circ} 11.771,2008\right)$. Com isso, o fluxo turístico gerado por essas melhorias, por sua vez, propicia um incremento de diversas outras atividades, como a realização de eventos. 


\subsection{Turismo de eventos: relevância e impactos}

Sabe-se que o turismo de eventos é a parte do turismo que leva em consideração o critério relacionado ao objetivo da atividade turística. É praticado com interesse profissional e cultural, e é uma das atividades econômicas que mais crescem no mundo atual (Hoeller, 2001).

O segmento de eventos surge, como uma estratégia de dinamização da atividade turística. Zanella (2006) aponta que 45\% dos deslocamentos humanos correspondem a participações em eventos, constituindo-se em uma das atividades que mais crescem nesse segmento. De acordo com o MTur (2013), o turismo de eventos é o segundo segmento que mais gera fluxo de movimentação turística. Além disso, o turista de eventos gasta mais que o de lazer (Andrade, 2013), e este público faz parte de um segmento sazonal.

Sabe-se que a sazonalidade é uma condição peculiar nos destinos turísticos, configurada como os períodos de alta e baixa temporada, esse fenômeno, poderá ser explicado pelo entendimento de fatores inerentes à diversas categorias e suas relações. Assim, para Butler (2001 como citado em Henz, Ruiz, \& Leite, 2014) a concentração da demanda em um destino pode ser explicada por fatores do próprio destino, como as condições climáticas, atrativos naturais e culturais, os eventos sociais, esportivos, religiosos ou outros, e por características da região demandante que, relacionados e incentivados por ações de implementação de estratégias de gestão, diversificação da oferta e segmentação, conduzem a um determinado padrão de sazonalidade do destino.

Sabe-se que o "produto" evento tem cada vez mais importância, por que não está totalmente submetido às normas da sazonalidade turística, constituindo-se até mesmo na área menos atingida nos períodos de crise. Há uma diferenciação entre o turismo tradicional e os eventos, pois estes se bem planejados podem se constituir em uma atração constante, em qualquer época, enquanto o turismo tradicional é mais acentuado em períodos de férias e feriados prolongados, incorporando fatores significativos de modismos (Andrade, 2013). Ou seja, o evento surge como uma possível solução para equilibrar os períodos de baixa temporada, porém, só vai conquistar o destino de um evento, quem captar os mesmos com diferenciais agregados, criatividade e preço justo, e realizar trabalhos não só no período da alta temporada.

Oliveira (2000) evidencia que 40\% do movimento turístico internacional acontece em função da realização de eventos, e é o tipo de turismo mais disputado pelos países, porque nessas ocasiões os produtos turísticos são vendidos em grandes quantidades, fomentando a 
venda de passagens aéreas e rodoviárias, diárias em hotéis, refeições, souvenires, produtos e serviços em geral, além da intensa contribuição na divulgação dos atrativos naturais, culturais e artificiais da região sede do evento.

Observa-se, que o processo advindo da promoção de eventos, poderá contribuir, de forma significativa, para a utilização dos equipamentos e serviços turísticos das regiões promotoras dos mesmos, bem como para divulgação de seus diversos atrativos. Essas estratégias comunicacionais estarão, por sua vez, implementando o crescimento da visitação e gerando a demanda específica, ou seja, elevando o fluxo turístico.

De modo geral, eventos são um dos principais fatores responsáveis pela geração de fluxo turístico em períodos de baixa temporada, embora não aconteça apenas nesses intervalos de tempo. Em aspectos econômicos, os valores obtidos pela captação desses turistas para o evento são de grande importância para economia do setor (Bem \& Assis, 2010).

Os mercados de eventos e turismo estão intimamente ligados a oferta e demanda, esta por sua vez trata-se de quão dispostos os consumidores estão para comprar os produtos ou serviços. Já aquela, se refere à quantidade de um produto ou serviço disponível para compra. Consequentemente, são influenciados por vários outros fatores como disponibilidade de tempo, nível de investimento na promoção do produto, condições climáticas entre outros.

Assim, os eventos em todo o mundo, compreendem uma alavanca motivadora para o turismo, devido a necessidade de planejamento e o consequente desenvolvimento dos destinos turísticos. Qualquer evento, sustentado por uma adequada avaliação de seu objetivo, se constitui em um "produto" cuja "venda" (realização) deve gerar movimentação econômica e lucro, o que poderá resultar em benefícios locais.

A atividade turística, discutida por uma abordagem sociocultural, observa nos deslocamentos das pessoas o momento do encontro cultural e das relações sociais existentes desse contato. O turismo provoca um impacto, uma transformação, um estranhamento, no qual diferentes culturas se relacionam. Esses impactos podem ser benéficos ou prejudiciais para a população receptora, dependendo da diferença de culturas, natureza do contato ou da percepção de cada indivíduo (Ignarra, 2014).

A movimentação turística é o processo mais utilizado para comercialização de um atrativo, que é uma característica importante no processo de escolha de um destino, de forma que uma imagem "malvista" antes ou após visitar o local, pode causar impactos no desenvolvimento dos destinos turísticos. De acordo com Cooper, Hall e Trigo (2011), existem três principais vertentes que podem classificar as influências da atividade turística nos municípios, que são: impactos ambientais, sociais e econômicos; e duas categorias que são os 
impactos positivos e os negativos.

Em relação aos impactos positivos e negativos do turismo, cita-se para os negativos, os efeitos de aculturação e imitação, ou seja, há uma troca de gostos e hábitos da cultura da comunidade receptora ao interagir com os gostos da emissora, podendo produzir o que é chamado de perda de identidade cultural. Além de prejuízos e barreiras sociais por intolerância, indiferença, xenofobia, racismo, idioma, o que pode corroborar negativamente para relações turísticas futuras. Já para os positivos, em âmbito cultural, contribui para a preservação do patrimônio histórico, artístico e cultural e facilita os laços de comunicação e entendimento entre os povos (Ignarra, 2014).

Não se pode negar que a atividade turística e os eventos movimentam recursos financeiros, geram empregos, permitem intercâmbio cultural, promovem o embelezamento paisagístico e podem melhorar a qualidade de vida da população. Em contrapartida, a falta de conhecimento de suas consequências danosas, a falta de preocupação com o bem-estar da população residente e com a preservação do ambiente por parte dos administradores, a falta de planejamento e um comportamento inadequado no uso dos recursos, podem levar a destruição dos potenciais natural e cultural de um lugar, apenas para citar alguns.

O segmento de turismo de eventos gera inúmeros impactos positivos, por ser um ramo do turismo que possui características diferentes, resultantes da estreita ligação entre turismo e eventos. Eventos por sua vez, é uma área pouco atingida em épocas de crise, não dependendo de regime governamental e nem influenciada pela sazonalidade da atividade turística, atingindo e gerando benefícios para os outros segmentos do turismo. Embora possam acarretar malefícios dependendo da forma como é executado.

\section{METODOLOGIA}

Para a consecução desse estudo foi realizada uma pesquisa descritiva de caráter exploratório com base em acervo bibliográfico, artigos científicos e demais estudos de entidades sobre eventos, turismo e turismo de eventos, pois sabe-se que a pesquisa bibliográfica é todo estudo que tenta quantificar processos de comunicação escrita (Pritchard, 1969). O estudo também contou com informações complementares, a partir da aplicação e análise de questionários junto às secretarias de turismo dos municípios pesquisados.

Sendo a população do estudo: os 10 municípios que compõem a microrregião do Litoral Sul Potiguar (Arês, Baía Formosa, Canguaretama, Espírito Santo, Goianinha, Montanhas, Pedro Velho, Senador Georgino Avelino, Tibau do Sul e Vila Flor), sua amostra foi composta pelos 03 principais municípios turísticos da referida localidade: Baía Formosa, 
Canguaretama e Tibau do Sul. Além disso, as secretarias de turismo destes validaram as informações dos eventos por meio de um questionário, utilizado como um dos instrumentos de coleta de dados. O questionário consiste em um conjunto de questões pré-elaboradas, de forma sistemática e sequencialmente disposta em itens que constituem o tema da pesquisa, com objetivo de suscitar dos entrevistados respostas por escrito sobre o assunto (Chizzotti, 2017).

A partir das informações coletadas, foram elaborados quadros representativos para compreender o contexto do turismo nos municípios da MRLS e dos eventos neles realizados, os quais correspondem, respectivamente, à relação dos municípios quanto ao turismo, isto é, na busca de uma interface capaz de gerar uma melhor compreensão acerca da temática e para fins desse estudo, entende-se por municípios turísticos, municípios de interesse turístico e município com potencial turístico, o que dispõe o quadro 01.

Quadro 1 - Interface município e turismo, para fins de entendimento conceitual desse estudo

\begin{tabular}{|c|l|}
\hline $\begin{array}{c}\text { Interface município } \\
\text { x turismo }\end{array}$ & $\begin{array}{l}\text { Conceituação } \\
\text { Os municípios turísticos (MT) são localidades que constituem um foco importante de } \\
\text { atração turística, uma vez que os turistas são incitados pelos atrativos naturais, } \\
\text { manifestações de cultura local e os atrativos feitos e gerenciados pelo homem, como } \\
\text { museus, parques temáticos e eventos especiais (Acerenza, 2008). Enfim, município } \\
\text { turístico é aquele que reúne as condições ideais para tal, a exemplo da existência de } \\
\text { uma rede entre os agentes locais (sociedade civil, iniciativa privada e poder público), } \\
\text { atrativos turísticos }{ }^{1} \text {, infraestrutura de apoio ao turismo e equipamentos e serviços } \\
\text { turísticos }{ }^{2} \text { que já possui e estão em constante melhoria, ao passo que os demais } \\
\text { municípios ainda estão buscando as melhorias necessárias para tal. }\end{array}$ \\
\hline Município de & $\begin{array}{l}\text { Podem ser considerados municípios de interesse turístico (MIT), localidades que } \\
\text { possuem atrativos turísticos e infraestrutura básica (dispõe de serviço médico, meios } \\
\text { de transporte, comunicação, etc.). Dessa forma, as condições de desenvolvimento } \\
\text { turístico de uma localidade são funções dos recursos, mas o crescimento da localidade } \\
\text { depende da capacidade de valorizá-los e da criação de novos fatores de atração, como } \\
\text { a criação de uma rede entre os agentes locais, que irá aproximar o poder público do } \\
\text { privado. }\end{array}$ \\
\hline Município com & $\begin{array}{l}\text { Entende-se município com potencial turístico (MPT), aqueles locais que possuem } \\
\text { recursos naturais e/ou culturais, pois estes são a principal motivação turística. Os } \\
\text { aspectos naturais somados às ordens social, cultural e econômica, podem ser } \\
\text { observados, como potencialidades para o desenvolvimento do turismo (Coriolano, }\end{array}$ \\
\hline potencial turístico
\end{tabular}

1 Locais, objetos, equipamentos, pessoas, fenômenos, eventos ou manifestações capazes de motivar o deslocamento de pessoas para conhecê-los. Dividem-se em 05 tipos, são eles: Atrativos Naturais; Atrativos Culturais; Atividades Econômicas; Realizações Técnicas, Científicas e Artísticas; Eventos Permanentes. (MTur, 2011).

${ }^{2}$ Informações básicas do município: distâncias, atrativos, equipamentos e serviços etc.; Sistemas de transportes: Rodoviárias, ferroviárias, aeroportos, portos, táxis, navios, trens, carros, ônibus, balsas, etc.; Sistemas de comunicações: Correios, sinal de operadoras de telefonia, internet, etc.; Sistemas de segurança: Delegacias, corpos de bombeiro, postos policiais, etc.; Equipamentos médico-hospitalares: Hospitais, clínicas, maternidades, prontos-socorros etc.; Outros Sistemas: Saneamento, água, eletricidade etc. (MTur, 2011).

${ }_{3}^{3}$ Meios de hospedagem; Alimentos e Bebidas; Entretenimento; Outros equipamentos e serviços turísticos. (MTur, 2011). 
2003). Contudo, o fato de haver uma potencialidade em um determinado lugar não significa que o mesmo pode ser considerado turístico, uma vez que para este último se concretizar são necessárias diversas intervenções, tais como a instalação de equipamentos e o provimento de infraestruturas, além da criação de uma rede entre os agentes locais.

Fonte: Dados da pesquisa, 2018.

O estudo buscou, ainda, elencar os principais eventos que são realizados nos 10 municípios da microrregião, apontando para um panorama mais próximo de um calendário de eventos regionais. Logo após, com a aplicação dos questionários junto às secretarias de turismo, obteve-se um ranking contendo os 10 principais eventos realizados nos 03 municípios turísticos (eventos estes, capazes de incrementar o fluxo turístico local), vale salientar que os itens dos quadros foram idealizados a partir da concepção sobre classificação de eventos defendida por Britto e Fontes (2006). Por sua vez, foi feito um levantamento referente às empresas de eventos que atuam formalmente na MRLS, isto é, aquelas que possuem CNPJ e estão cadastradas junto ao Ministério do Turismo (MTur, 2018) por meio do cadastro de pessoas físicas e jurídicas que atuam no setor turístico (Cadastur).

Com base nos dados coletados e utilizando a técnica de análise de conteúdo, o estudo foi capaz de reunir e compilar informações no contexto do turismo, dos eventos e do turismo de eventos das localidades em que a pesquisa foi realizada.

\section{ANÁLISE E DISCUSSÃO DOS RESULTADOS}

Dentre os resultados e discussões desse estudo, é possível identificar como os municípios se relacionam com a atividade turística, isto é, em que contexto eles se encontram; quais os principais eventos que se realizam nos 10 municípios da MRLS; compreender quais desses eventos realizam-se nos principais destinos turísticos; e mapear as empresas formais que atuam no setor de eventos; para entender quais os eventos e que impactos possíveis podem causar na localidade, uma vez que o fluxo turístico se configura como um fator determinante para tal.

\subsection{Municípios e interface com o turismo na realidade da Microrregião do}

\section{Litoral Sul Potiguar}

A partir dos conhecimentos obtidos nos estudos sobre conceituações (ver quadro 01) envolvendo turismo e eventos, foi necessário, ainda, entender a realidade da MRLS sobre algumas perspectivas, dentre elas, se a mesma compreendia municípios turísticos (MT), com interesse turístico (MIT) ou com potencial turístico (MPT). Diante disso, não se pretendeu 
limitar em categorias os municípios e como os mesmos se relacionam com o turismo, ao contrário, sentiu-se a necessidade de compreender o contexto local de uma região diversificada e em estágios distintos de evolução dessa atividade por meio de uma análise pontual, uma vez que aquela é propícia à prática dessa, já que possui inúmeros elementos para um desenvolvimento turístico real. Mesmo com poucos estudos sobre a MRLS, percebe-se que há alguns anos novos estudos estão sendo desenvolvidos e que apontam para evidências dos atrativos turísticos. Observados em um estudo realizado por Virginio (2015), retrata um mapeamento e potencialidades turísticas na forma de trilhas existentes na MRLS, apontando alguns dos atrativos naturais daquela região.

Isto posto, percebeu-se que na microrregião estão contidos 4 (quatro) municípios turísticos, 4 (quatro) com potencial turístico e 2 (dois) com interesse turístico, vide quadro 02.

Quadro 2 - Municípios da MRLS e sua interface com o turismo

\begin{tabular}{|l|c|c|c|c|c|c|}
\hline $\begin{array}{c}\text { Municípios da } \\
\text { MRLS }\end{array}$ & $\begin{array}{c}\text { Atrativos } \\
\text { turísticos }\end{array}$ & $\begin{array}{c}\text { Infraestrutura de } \\
\text { apoio ao turismo }\end{array}$ & $\begin{array}{c}\text { Serviços e } \\
\text { equipamentos turísticos }\end{array}$ & PT & MIT & MT \\
\hline Arês & $\mathrm{X}$ & $\mathrm{X}$ & & & $\mathrm{X}$ & \\
\hline Baía Formosa & $\mathrm{X}$ & $\mathrm{X}$ & $\mathrm{X}$ & & & $\mathrm{X}$ \\
\hline Canguaretama & $\mathrm{X}$ & $\mathrm{X}$ & $\mathrm{X}$ & $\mathrm{X}$ & & \\
\hline Espírito Santo & $\mathrm{X}$ & & $\mathrm{X}$ & & $\mathrm{X}$ \\
\hline Goianinha & $\mathrm{X}$ & $\mathrm{X}$ & & $\mathrm{X}$ & & \\
\hline Montanhas & $\mathrm{X}$ & $\mathrm{X}$ & & $\mathrm{X}$ & & \\
\hline Pedro velho & $\mathrm{X}$ & $\mathrm{X}$ & $\mathrm{X}$ & \\
\hline $\begin{array}{l}\text { Senador Georgino } \\
\text { Avelino }\end{array}$ & $\mathrm{X}$ & $\mathrm{X}$ & & & & $\mathrm{X}$ \\
\hline Tibau do Sul & $\mathrm{X}$ & & $\mathrm{X}$ & & \\
\hline Vila Flor & $\mathrm{X}$ & & & & \\
\hline
\end{tabular}

Fonte: Dados da pesquisa, 2018.

Considerando que a microrregião do Litoral Sul Potiguar é composta por diversas áreas de litoral, além de trilhas, etc. Podem acontecer inúmeras atividades de lazer ligadas ao cunho marítimo, cultural ou de aventura. Essas atividades estão ligadas a empresas privadas, assim sendo comercializadas e organizadas por estas.

Apesar das diversas formas de entretenimento que podem ser desenvolvidas na microrregião, três cidades presentes no quadro 02 não dispõem de infraestrutura turística, além de seis que dispõem de serviços e equipamentos. As cidades de Espírito Santo, Montanhas, Senador Georgino Avelino e Vila Flor são entendidas como potenciais turísticos, pois não possuem infraestrutura de apoio ao turismo, nem equipamentos e serviços turísticos, 
apenas atrativos, sejam eles, naturais e/ou culturais. Apesar de esses municípios terem potenciais turísticos, encontram-se em patamares diferentes, a exemplo das cidades de Vila Flor e Senador Georgino Avelino, já que a movimentação do fluxo turístico nessas cidades é diferente. Considerando que os atrativos turísticos que cada uma possui são determinantes para isso, sendo a primeira mais voltada ao turismo cultural e ecoturismo e a segunda mais voltada ao turismo de lazer.

Por outro lado, os municípios de Arês e Pedro Velho encontram-se como de interesse turístico, pois além de possuir potencial, sabe-se que agentes locais, sejam da iniciativa privada ou do poder público local, entre outros, buscam atuação em rede e começam a dar os primeiros passos para a formação de iniciativas em torno do desenvolvimento da atividade turística.

Já os municípios de Baía Formosa, Canguaretama, Tibau do Sul e Goianinha são apontados como municípios turísticos, porém este último não se encontra no mesmo patamar que os outros municípios, considerando que ele não possui tantos atrativos turísticos (e, consequentemente, menos fluxo turístico). Quanto aos outros municípios que possuem atrativos naturais, como praias e cachoeiras; além de atrativos culturais, como igrejas e construções antigas que fazem parte do acervo histórico de cada local e constituem um foco importante para o turismo cultural. Os eventos permanentes, a exemplo a festa dos mártires de Cunhaú na cidade de Canguaretama, também são muito relevantes para esses destinos. A soma destes elementos corrobora para o aumento da movimentação do fluxo turístico e fazem dos municípios analisados juntamente com toda a infraestrutura de apoio ao turismo e dos diversos equipamentos e serviços que possuem municípios turísticos e importantes no cenário estadual.

\subsection{Eventos nos municípios da microrregião do Litoral Sul Potiguar e impactos possíveis}

Não se pode negar que os eventos e a atividade turística movimentam recursos financeiros, geram empregos, permitem intercâmbio cultural, promovem o embelezamento paisagístico e podem melhorar a qualidade de vida da população. Em contrapartida, a falta de conhecimento de suas consequências danosas, a falta de preocupação com o bem-estar da população residente e com a preservação do ambiente, entre outros, pode levar a destruição dos potenciais natural e cultural de um lugar.

Os dados apresentados no estudo sobre o setor de eventos realizado pela ABEOC e 
SEBRAE (2013) reforçam a relevância desse setor como gerador de renda, emprego e impostos. No ano de 2013, foram realizados 590.913 eventos nos 9.445 espaços disponíveis no País, reunindo 202.171.787 pessoas e gerando uma receita estimada de R \$ 209,2 bilhões.

Assim, o presente estudo, elaborou um panorama dos principais eventos que se realizam nos municípios da microrregião do Litoral Sul Potiguar (ver quadro 03), no intuito de compreender melhor a dinâmica desse setor e sua relação com um possível aumento no fluxo de turistas e, mais ainda, os impactos possíveis advindos dele.

Quadro 3 - Panorama dos principais eventos realizados nos 10 municípios da MRLS

\begin{tabular}{|c|c|c|c|c|c|c|}
\hline Cidade & Nome do evento & Local & $\begin{array}{c}\text { Perfil do } \\
\text { público }\end{array}$ & $\begin{array}{l}\text { Estimativa de } \\
\text { público }\end{array}$ & Porte & Data \\
\hline \multirow{2}{*}{ Arês } & Carnaval & Espaço externo & Geral & $\begin{array}{c}1500 \text { a } 2000 \\
\text { pessoas }\end{array}$ & Médio & $\begin{array}{l}\text { Data } \\
\text { móvel }\end{array}$ \\
\hline & Festa junina & Espaço externo & Geral & 3000 pessoas & Médio & $24 / 06$ \\
\hline \multirow{3}{*}{ Baía Formosa } & $\begin{array}{c}\text { Festival } \\
\text { Gastronômico }\end{array}$ & $\begin{array}{l}\text { Mirante de Baía } \\
\text { formosa }\end{array}$ & Dirigido & De 4 a 5 mil & Médio & $\begin{array}{c}\text { Data } \\
\text { Móvel }\end{array}$ \\
\hline & $\begin{array}{l}\text { Festival de } \\
\text { Cinema }\end{array}$ & $\begin{array}{c}\text { Mirante de Baía } \\
\text { Formosa }\end{array}$ & Dirigido & $\begin{array}{c}\text { De } 3 \text { mil a } 4 \\
\text { mil pessoas }\end{array}$ & Médio & $\begin{array}{l}\text { Data } \\
\text { móvel }\end{array}$ \\
\hline & Formosa Folia & Praça pública & Geral & $8 \mathrm{mil}$ & Grande & $\begin{array}{l}\text { Data } \\
\text { móvel }\end{array}$ \\
\hline \multirow{4}{*}{ Canguaretama } & $\begin{array}{l}\text { Festa dos } \\
\text { Mártires }\end{array}$ & $\begin{array}{c}\text { Capela dos } \\
\text { mártires e Centro } \\
\text { da cidade }\end{array}$ & Geral & $\begin{array}{l}8 \text { mil a } 10 \text { mil } \\
\text { pessoas }\end{array}$ & Grande & $\begin{array}{l}16 \text { de } \\
\text { julho }\end{array}$ \\
\hline & $\begin{array}{l}\text { Festa da } \\
\text { padroeira }\end{array}$ & $\begin{array}{l}\text { Centro da cidade } \\
\text { de Canguaretama }\end{array}$ & Geral & Mais de 5 mil & Grande & $\begin{array}{c}\text { De } 29 / 11 \\
\text { a } 08 / 12\end{array}$ \\
\hline & $\begin{array}{l}\text { Santo Antônio do } \\
\text { povo }\end{array}$ & Praça pública & Geral & 10 mil pessoas & Grande & $\begin{array}{l}\text { De } 10 / 06 \\
\text { a } 12 / 06\end{array}$ \\
\hline & Carnaval & Barra do Cunhaú & Geral & $\begin{array}{c}\text { De } 5 \text { a } 10 \text { mil } \\
\text { pessoas }\end{array}$ & Grande & $\begin{array}{l}\text { Data } \\
\text { móvel }\end{array}$ \\
\hline \multirow{2}{*}{ Espírito Santo } & $\begin{array}{c}\text { Emancipação } \\
\text { política }\end{array}$ & Praça pública & Geral & Mais de 4000 & Médio & $04 / 01$ \\
\hline & $\begin{array}{l}\text { Festa da } \\
\text { padroeira }\end{array}$ & Praça pública & Geral & Mais de 5000 & Grande & $\begin{array}{c}23 / 01 \mathrm{a} \\
01 / 02\end{array}$ \\
\hline \multirow{3}{*}{ Goianinha } & $\begin{array}{c}\text { Emancipação } \\
\text { política }\end{array}$ & Praça pública & Geral & $\begin{array}{c}\text { Mais de } 3000 \\
\text { pessoas }\end{array}$ & Médio & $09 / 11$ \\
\hline & $\begin{array}{c}\text { Festa da } \\
\text { padroeira }\end{array}$ & Praça pública & Geral & $\begin{array}{c}\text { Mais de } 5000 \\
\text { pessoas }\end{array}$ & Grande & $\begin{array}{c}06 \text { a } 08 \text { de } \\
\text { abril }\end{array}$ \\
\hline & $\begin{array}{c}\text { Semana de arte e } \\
\text { cultura }\end{array}$ & $\begin{array}{c}\text { Ginásio } \\
\text { poliesportivo }\end{array}$ & Geral & 2500 pessoas & Médio & $\begin{array}{l}\text { Data } \\
\text { móvel }\end{array}$ \\
\hline
\end{tabular}


Darlyne Fontes Virginio, Yohana Silva Moreira, Paulo Messias da Paz de Lima e Laynara Silva Chacon

\begin{tabular}{|c|c|c|c|c|c|c|}
\hline \multirow{4}{*}{ Montanhas } & $\begin{array}{l}\text { Aniversário da } \\
\text { cidade }\end{array}$ & Praça pública & Geral & $\begin{array}{c}6000 \text { a } 7000 \\
\text { pessoas }\end{array}$ & Grande & $20 / 07$ \\
\hline & Vaquejada & $\begin{array}{c}\text { Pátio de } \\
\text { vaquejada }\end{array}$ & Dirigido & Mais de 5000 & Grande & $\begin{array}{l}\text { Data } \\
\text { móvel }\end{array}$ \\
\hline & Carnaval & Praça pública & Geral & $\begin{array}{c}\text { Menos de } \\
3000\end{array}$ & Médio & $\begin{array}{l}\text { Data } \\
\text { móvel }\end{array}$ \\
\hline & Arraiá & Praça pública & Geral & 2500 pessoas & Médio & $24 / 06$ \\
\hline \multirow{3}{*}{ Pedro Velho } & $\begin{array}{l}\text { São Pedro do } \\
\text { Povão }\end{array}$ & Praça pública & Geral & 3000 pessoas & Médio & $26 / 06$ \\
\hline & $\begin{array}{c}\text { Festa da } \\
\text { padroeira }\end{array}$ & Praça pública & Geral & 2500 pessoas & Médio & $\begin{array}{c}28 / 11 \mathrm{a} \\
08 / 12\end{array}$ \\
\hline & $\begin{array}{l}\text { Emancipação } \\
\text { política }\end{array}$ & Praça pública & Geral & 2500 pessoas & Médio & $10 / 05$ \\
\hline \multirow{3}{*}{$\begin{array}{c}\text { Senador } \\
\text { Georgino } \\
\text { Avelino }\end{array}$} & Carnaval & Praça pública & Geral & 2500 pessoas & Médio & $\begin{array}{l}\text { Data } \\
\text { móvel }\end{array}$ \\
\hline & Réveillon & Praça pública & Geral & 2500 pessoas & Médio & $31 / 12$ \\
\hline & $\begin{array}{l}\text { Festa de Santo } \\
\text { Antônio achado }\end{array}$ & Barragem & Geral & 3000 pessoas & Médio & $12 / 06$ \\
\hline \multirow{3}{*}{ Vila Flor } & $\begin{array}{c}\text { Semana } \\
\text { Evangélica }\end{array}$ & Praça pública & Dirigido & Mais de 10000 & Grande & 01 a $04 / 11$ \\
\hline & $\begin{array}{c}\text { Festa da } \\
\text { padroeira }\end{array}$ & Praça pública & Geral & 5000 pessoas & Médio & $27 / 03$ \\
\hline & Festival junino & Ginásio & Geral & 2000 pessoas & Médio & $\begin{array}{l}\text { Data } \\
\text { móvel }\end{array}$ \\
\hline \multirow{6}{*}{ Tibau do Sul } & Fest Bossa e Jazz & $\begin{array}{l}\text { Estacionamento } \\
\text { e Pipa open air }\end{array}$ & Dirigido & 8 mil pessoas & Grande & $\begin{array}{l}\text { Data } \\
\text { móvel }\end{array}$ \\
\hline & FliPipa & Pipa open air & Dirigido & $\begin{array}{l}\text { Mais de } 5 \text { mil } \\
\text { pessoas }\end{array}$ & Grande & $\begin{array}{l}\text { Data } \\
\text { móvel }\end{array}$ \\
\hline & FlipAut & Casa do Artesão & Dirigido & $\begin{array}{c}2 \text { a } 3 \text { mil } \\
\text { pessoas }\end{array}$ & Médio & $\begin{array}{l}\text { Data } \\
\text { móvel }\end{array}$ \\
\hline & $\begin{array}{c}\text { Festival } \\
\text { Gastronômico da } \\
\text { Pipa }\end{array}$ & Estacionamento & Dirigido & $\begin{array}{l}\text { Mais de } 5 \text { mil } \\
\text { pessoas }\end{array}$ & Grande & $\begin{array}{l}\text { Data } \\
\text { móvel }\end{array}$ \\
\hline & $\begin{array}{l}\text { Festa do } \\
\text { padroeiro }\end{array}$ & Praça Pública & Geral & 4 mil pessoas & Médio & $20 / 01$ \\
\hline & Carnaval & Praça pública & Geral & Mais de 5000 & Grande & $\begin{array}{l}\text { Data } \\
\text { móvel }\end{array}$ \\
\hline
\end{tabular}

Fonte: Dados da pesquisa, 2018. 
Dessa forma, percebe-se que existe um considerável número de eventos que são realizados na MRLS (totalizando 33 eventos, apenas aqueles tidos como os principais, com base nas pesquisas realizadas), sendo a maior parte de médio porte, isto é, aqueles com o público estimado entre 500 e 5000 pessoas (Britto e Fontes, 2006). Dados que denotam grande movimentação de pessoas em torno dos mesmos se considerado que a maior parte desses municípios possui, em média, uma população que varia de 8000 a 14000 pessoas, como é o caso de Baía Formosa, Espírito Santo e Pedro Velho (Instituto Brasileiro de Geografia e Estatística [IBGE], 2018).

Outro fator que chama a atenção é que a maior parte desses eventos é realizada em praça pública, isto é, aberto ao público em geral e contando com a infraestrutura básica disponibilizada pelo município. Assim, esses eventos precisam montar toda uma estrutura de palco, tendas, sonorização, iluminação, entre outros, para ocorrer, já que em espaços externos isso se torna essencial.

Contudo, quase a totalidade dos eventos listados no quadro 03 são organizados pelas prefeituras municipais e se tratam de comemorações tradicionais e já fixas no calendário local, como é o caso do carnaval, festa de padroeiro/a, festas juninas e emancipação política. Tendo destaque para uma maior variedade em destinos turísticos como Tibau do Sul e Baía Formosa que investem em festivais gastronômicos, de cinema e musicais.

\subsection{Eventos nos municípios turísticos da MRLS: Análise, relação e impactos}

Refletindo sobre os eventos realizados somente nos municípios turísticos de Baía Formosa, Canguaretama e Tibau do Sul, elaborou-se um ranking com os 10 principais eventos realizados na microrregião e que geram fluxo turístico, ou seja, aqueles que atraem pessoas para a localidade com a motivação de participar de determinado evento e que pernoitam no local. Para a elaboração desse ranking (ver quadro 04), foi necessário consultar e validar os dados obtidos junto às secretarias de turismo dos referidos municípios pesquisados.

Pesquisou-se, com base em Zucarato e Sansolo (2006), sobre a existência de possíveis indicadores capazes de determinar a influência ou a contribuição do fluxo turístico a partir dos eventos para o desenvolvimento do turismo local, buscando embasar ainda mais o estudo, porém, não foi encontrado na literatura um indicador com capacidade para mensurar o que se pretendia reforçando a carência de estudos e pesquisas que envolvem esses quesitos. 


\begin{tabular}{|c|c|c|c|c|c|}
\hline \multicolumn{2}{|c}{ Quadro 4-Os principais eventos dos Municípios Turísticos da MRLS } \\
\hline Município & Nome do evento & Perfil & $\begin{array}{c}\text { Estimativa de } \\
\text { público }\end{array}$ & Porte & Data \\
\hline Canguaretama & Festa dos Mártires & Geral & De 8 a 10 mil & Grande & 16 de julho \\
\hline Baía Formosa & Formosa Folia & Geral & 8 mil & Grande & Data móvel \\
\hline Tibau do Sul & Fest bossa e jazz & Dirigido & 8 mil & Grande & Data móvel \\
\hline Tibau do Sul & FliPipa & Dirigido & De 5 a 6 mil & Grande & Data móvel \\
\hline Tibau do Sul & $\begin{array}{c}\text { Festival Gastronômico da } \\
\text { Pipa }\end{array}$ & Dirigido & De 5 a 6 mil & Grande & Data móvel \\
\hline Canguaretama & Carnaval de Barra do Cunhaú & Geral & 5 mil & Grande & Data móvel \\
\hline Tibau do Sul & Carnaval de Tibau/Pipa & Geral & 5 mil & Grande & Data móvel \\
\hline Baía Formosa & $\begin{array}{c}\text { Festival gastronômico de Baía } \\
\text { Formosa }\end{array}$ & Dirigido & 4 mil & Médio & Data móvel \\
\hline Baía Formosa & $\begin{array}{r}\text { Festival de Cinema de Baía de } \\
\text { Baía Formosa }\end{array}$ & Dirigido & 3 mil & Médio & Data móvel \\
\hline Tibau do Sul & FlipAut & Dirigido & De 2 a 4 mil & Médio & Data Móvel \\
\hline
\end{tabular}

Fonte: Dados da pesquisa, 2018.

Os eventos descritos no quadro 04 constituem a oferta turística dos municípios onde ocorrem, sendo responsáveis por incrementar o fluxo e divulgar as potencialidades do referido destino, eles foram dispostos no quadro conforme a estimativa de público informada pelas respectivas secretarias de turismo.

O município de Tibau do Sul responde por metade desses eventos e já atua com foco para o desenvolvimento do turismo de eventos há alguns anos, firmando em seu calendário o festival gastronômico da Pipa que já figura entre os maiores do estado na modalidade. Dessa forma, a partir da oferta desses eventos, o destino se posiciona no mercado e capta demanda turística. Eles podem ser configurados como sendo uma possível solução diante da sazonalidade da atividade turística, contribuindo para que o destino se desenvolva mesmo nos meses de baixa estação, uma vez que permitem maior estabilidade de emprego no setor turístico.

Esses eventos podem ser um dos motivos fundamentais para inúmeros turistas visitarem esses destinos, uma vez que possuem em sua maioria, uma data específica. Permitindo ao turista se organizar para participar do evento e ainda, conhecer os atrativos naturais e culturais, esses somados compreendem uma grande força no momento de atrair essa 
demanda. Portanto, os eventos que acontecem nestes destinos são ferramentas para a promoção destas cidades em âmbito nacional.

Considerando que os eventos e o turismo são os pontos principais deste estudo compreendeu-se que era essencial saber quem eram as empresas formais de eventos da MRLS, no intuito de averiguar se elas atuam na produção desses eventos, contudo, a pesquisa não obteve retorno das empresas existentes. Apesar disso, utilizando como fonte o Cadastur, foi possível identificar que existem somente 03 empresas formais cadastradas que atuam no setor de eventos e estão localizadas em Tibau do Sul (01) e Goianinha (02). De acordo com a Lei Geral do Turismo nº11.771 (2008), uma empresa organizadora de eventos é aquela que realiza serviços de gestão, planejamento, organização, promoção, coordenação, operacionalização, produção e assessoria de eventos. Já para Mendonça e Perozin (2014), a empresa organizadora de eventos pode optar por trabalhar com todas essas ações ou mesmo se especializar em algumas delas.

O número reduzido de empresas pode ser explicado pelo fato de que o mercado de eventos na Microrregião do Litoral Sul Potiguar ainda é considerado uma área nova, na qual muitos ainda atuam na informalidade. Sendo assim, acredita-se que existem diversas empresas de eventos que atuam na MRLS, porém, muitas ainda sem preparo técnico para atuar no segmento, e essa falta de conhecimento associado a outros fatores faz com que essas empresas permaneçam na ilegalidade, o que torna dificultoso o processo de mensuração do seu alcance em nível regional.

Além disso, outra hipótese é que esse fato pode estar diretamente ligado ao déficit de profissionais devidamente qualificados para atuar no setor. Contudo, no ano de 2014 surgiu o curso técnico em eventos no município de Canguaretama, ofertado pelo Instituto Federal de Educação, Ciência e Tecnologia do Rio Grande do Norte - IFRN, tal feito vem mudando a dinâmica desse setor, pois já existem turmas formadas com profissionais qualificados e uma série de projetos de pesquisa e de extensão sendo desenvolvidos com enfoque no setor de turismo e eventos, sendo o eixo turismo, hospitalidade e lazer, o principal foco tecnológico do referido campus do IFRN.

Com relação aos entraves, ora mencionados, como a falta de estudos e pesquisas do setor, empresas não formalizadas na MRLS e poucos profissionais qualificados, é sabido que os impactos negativos possíveis devem ser levantados e observados sob pena de agravar ainda mais os gargalos já existentes, assim, pode-se citar aculturação, poluição e elevação nos preços, apenas para citar alguns. Já como impactos positivos possíveis, tem-se o fortalecimento e a diversificação de atrativos nos destinos turísticos, contribuição para a 
preservação do patrimônio histórico, dinamização da economia local e auxílio a mudanças nos processos naturais que realçam valores ambientais (Cooper, Hall, \& Trigo, 2011). A partir disso os referidos autores compreendem diferentes categorias de impactos: ambientais, econômicos e sociais nos destinos, esses estão elencados no quadro 05.

Quadro 5 - Alguns impactos gerados pelo turismo

\begin{tabular}{|c|c|c|c|}
\hline Categoria & Ambiental & Econômico & Social \\
\hline \multirow[b]{2}{*}{ Positivo } & Manutenção da biodiversidade & Criação de emprego & Renovação comunitária \\
\hline & Conservação arquitetônica & $\begin{array}{ll}\text { Investimentos } & \text { em } \\
\text { infraestrutura e serviços } & \\
\end{array}$ & $\begin{array}{l}\text { Fortalecimento dos valores e } \\
\text { tradições comunitárias }\end{array}$ \\
\hline \multirow{2}{*}{ Negativo } & $\begin{array}{l}\text { Mudanças nos processos } \\
\text { ambientais naturais }\end{array}$ & $\begin{array}{l}\text { Inflação localizada } \\
\text { aumento de preço }\end{array}$ & $\begin{array}{l}\text { Mudanças na estrutura } \\
\text { comunitária }\end{array}$ \\
\hline & Perda da biodiversidade & $\begin{array}{l}\text { Maiores desempregos } \\
\text { sazonais }\end{array}$ & $\begin{array}{l}\text { Aumento da atividade } \\
\text { criminal }\end{array}$ \\
\hline
\end{tabular}

Fonte: Adaptado de Cooper, Hall e Trigo, 2011.

Dessa forma, os impactos possíveis advindos do turismo e dos eventos são inúmeros e se apresentam em categorias diversas, podendo interferir diretamente no desenvolvimento dessas atividades, uma vez que, tanto corrobora para a melhoria da movimentação de fluxo turístico quanto para o seu declínio, já que as repercussões dessas influências chegam aos turistas de forma rápida e se forem negativos, o destino perde sua visibilidade positiva.

Ao obter, reunir e analisar tal montante de informações sobre turismo e eventos nos municípios turísticos da MRLS, percebe-se que os impactos negativos possíveis são reais e já estão instalados, porém, ainda com grandes possibilidades de direcionamento por meio de um planejamento adequado. Outrossim, depreende-se com clareza que os impactos positivos possíveis se configuram com o incremento do turismo de eventos como alternativa para amenizar os períodos de baixa temporada.

Por fim, vale ressaltar que há uma necessidade em tratar da temática com mais afinco, especialmente, na literatura que ainda tem explorado de forma tímida esse assunto. Mesmo que, em detrimento ao que afirmam estudiosos sobre turismo de eventos Hoeller (2001); Zanella (2006); Andrade (2013); Oliveira (2000) esse seja o segmento que mais cresce no mundo. 


\section{CONSIDERAÇÕES FINAIS}

De acordo com o que foi pesquisado, pode-se perceber que a microrregião Litoral Sul Potiguar tem muito potencial a ser explorado para o turismo de eventos que ainda caminha a passos lentos, pois se houver planejamento apropriado em relação a essa ramificação do turismo, possivelmente, o fluxo de turistas aumentará, podendo assim, gerar um retorno significativo para as cidades, visto que a maioria delas tem potencial turístico para se desenvolver. Além disso, este segmento pode ser entendido como uma ferramenta crucial para os destinos em períodos sazonais.

Assim, a movimentação turística em diversos municípios da MRLS pode ser influenciada por eventos que são realizados em alguns desses destinos. Apesar disso, a temática ainda é pouco explorada e, por isso, houve percalços durante a pesquisa, principalmente, quando o seu desenvolvimento dependia de outras pessoas, como dos secretários de turismo ou das empresas formais do setor de eventos que atuam na região.

Entretanto, apesar da pouca quantidade de pesquisas existentes e a falta de contribuição de algumas partes envolvidas, conseguiu-se desenvolver bons frutos da pesquisa, como por exemplo, a interface entre o turismo e os municípios da região, bem como a elaboração de um panorama com 33 principais eventos que ocorrem nos 10 municípios da MRLS. Para, além disso, estabelecer um ranking de 10 eventos capazes de atrair fluxo turístico e o levantamento das empresas formais do setor de eventos da MRLS também foram igualmente relevantes e esclarecedores para o conhecimento e potencial que representam no cenário estadual.

É inegável a influência dos eventos no fluxo turístico e divulgação das potencialidades dos municípios turísticos, como também na movimentação da economia, embora esses também possam trazer seus danos a nível local, como a aculturação e diversos impactos ambientais.

A partir disso, pode-se levantar a hipótese de que o crescimento do turismo de eventos na MRLS pode alavancar os negócios na área e propiciar a abertura de novas empresas, bem como a geração de novos empregos. Dessa forma, deve-se chamar atenção para a importância da qualificação e formação dos profissionais que atuam nesse setor, pois serão necessárias pessoas que tenham uma formação e profissionalização adequada para possível atuação.

Diante disso, pode-se concluir que mesmo o turismo de sol e mar sendo o carro chefe dos municípios turísticos da MRLS, o turismo de eventos é um segmento importante para o desenvolvimento desses, sendo relevante tratar o turismo e a realização de eventos como áreas 
estratégicas que podem fomentar e contribuir com a dinamização econômica local quando trabalhados de forma conjunta.

\section{REFERÊNCIAS}

Acerenza, M. A. (2008). Gestion municipal del turismo. Mexico: Editorial Trillas Sa De Cv.

Andrade, R. B. (2013). Manual de Eventos. (4a.ed.). Caxias do Sul, RS: EDUCS.

Associação Brasileira de Empresas de Eventos \& Serviço Brasileiro de Apoio às Micro e Pequenas Empresas. (2013). II Dimensionamento econômico da Indústria de Eventos. Recuperado em 10, junho, 2018, de http://www.abeoc.org.br/wp-content/uploads/2014/10/IIdimensionamento-setor-eventos-abeoc-sebrae-171014.pdf

Barreto, M. (2012). Manual de iniciação ao estudo do Turismo. (20a. ed.). Campinas, SP: Papirus.

Bem, K. \& Assis, M. A. (2010). A importância dos clubes de Caicó para o desenvolvimento do turismo de eventos local. Caderno Virtual do Turismo, 10(2), 92-94.

Britto, J. \& Fontes, N. (2006). Estratégias para Eventos: Uma ótica do marketing e do Turismo. (2a. ed.). São Paulo: Aleph.

Canton, A. M. (2009). Evento, um potencializador de negócios. Barueri, SP: Manole.

Chizzotti, A. (2017). Pesquisa em Ciências humanas e Sociais. (12a. ed.). São Paulo: Cortez.

Cooper, C., Hall, C. M., \& Trigo, L. G. G. (2011). Turismo contemporâneo. Rio de Janeiro: Elsevier.

Coriolano, L. N. M. T. (Org). (2003). O Turismo de inclusão e o desenvolvimento local. Fortaleza: FUNECE.

Federação do Comércio de Bens, Serviços e Turismo do RN. (2015). Carnaval de Natal injetou mais de $R \$ 54$ milhões na economia. Recuperado em 25, junho, 2018, de http://fecomerciorn.com.br/noticias/carnaval-em-natal-injetou-mais-de-r-54-milhoes-naeconomia-diz-estudo-da-fecomercio.

Giacaglia, M. C. (2003). Organização de Eventos: Teoria e Prática. São Paulo: Thomson Learning.

Henz, A. P., Ruiz, T. C. D., \& Leite, F. C. L. (2014). Um ensaio teórico sobre a sazonalidade. VIII Fórum Internacional de Turismo do Iguassu, Foz do Iguaçu/PR.

Hoeller, E. H. (2001). Turismo de Eventos: Centreventos Cau Hansen de Joinville/SC. In:

Ansarah, M. G. R. (Org.). Turismo: Segmentação de Mercado. São Paulo: Futura.

Ignarra, L. (2014). Fundamentos do Turismo. (3a. ed.). Rio de Janeiro: SENAC.

Instituto Brasileiro de Geografia e Estatística. (2018). População estimada dos municípios de Baia Formosa, Espírito Santo e Pedro Velho. Recuperado em 15, janeiro, 2019, de https://cidades.ibge.gov.br/brasil/rn/panorama. 
Lei Geral do Turismo $n^{\circ} 11.771$ de 17 de setembro de 2008. (2008). Dispõe sobre a Política Nacional de Turismo e dá outras providências. Brasília, DF. Recuperado em 05, julho, 2018, de http://www.planalto.gov.br/ccivil_03/_ato2007-2010/2008/lei/111771.htm.

Matias, M. (2013). Organização de Eventos: Procedimentos e Técnicas. (6a. ed.). São Paulo: Manole.

Mendonça, M \& Perozin, J. (2014). Planejamento e Organização de Eventos. São Paulo: Erica.

Ministério do Turismo. (2018). Cadastro das empresas formais organizadoras de eventos que atuam na MRLS. Recuperado em 22, agosto, 2018, de

https://cadastur.turismo.gov.br/hotsite/\#!/public/souturista/inicio.

Ministério do Turismo. (2011). Inventário da Oferta Turística. Recuperado em 27, outubro, 2018, de

http://www.inventario.turismo.gov.br/invtur/downloads/formularios/inventariacao_da_oferta turistica.pdf

Ministério do Turismo. (2013). Os 10 anos do Ministério do Turismo. Recuperado em 12, novembro, 2018, de

http://www.turismo.gov.br/sites/default/turismo/noticias/todas_noticias/Noticias_download/li vro_10_anos_.pdf.

Oliveira, A. P. (2000). Turismo e desenvolvimento: planejamento e organização. (2a. ed.).

São Paulo: Atlas.

Pritchard, A. (1969). Statistical, bibliography or biometrics. Journal of Documentation, 25(4), 348-349.

Serviço Nacional de Aprendizagem Comercial. (2000). Eventos: Oportunidades de novos negócios. Rio de Janeiro: SENAC Nacional.

Virginio, D. F. (2015). Trilhas da Microrregião do Litoral Sul/RN: mapeamento e potencialidades. Natal, RN: Editora IFRN.

Zanella, L. (2006). Manual de Organização de Eventos: planejamento e operacionalização. (4a. ed.). São Paulo: ATLAS.

Zucarato, A, G., \& Sansolo, D. G. (2006). Uso de indicadores na pesquisa em turismo. IV SeminTUR - Seminário de Pesquisa em Turismo do MERCOSUL. Universidade de Caxias do Sul. Caxias do Sul, RS, Brasil.

FORMATO PARA CITAÇÃO DESTE ARTIGO

VIRGINIO, D. F., MOREIRA, Y. S., LIMA, P. M. P., \& CHACON, L. S. (2019). Interface entre municípios, Turismo e eventos: Um olhar para a Microrregião do Litoral Sul Potiguar e impactos possíveis. Revista de Turismo Contemporâneo, 7(1), 49-70. https://doi.org/10.21680/2357-8211.2019v7n1ID16931 